\title{
Every Child on the Map: A Theory of Change Framework for Improving Childhood Immunization Coverage and Equity Using Geospatial Data and Technologies
}

Sarah Cunard Chaney ${ }^{1}$, MSc, MPH; Patricia Mechael ${ }^{1}$, MHS, PhD; Nay Myo Thu ${ }^{2}, \mathrm{MSc}, \mathrm{MBBS} ;$ Mamadou S Diallo ${ }^{3}$, $\mathrm{PhD}$; Carine Gachen ${ }^{4}$, MSc

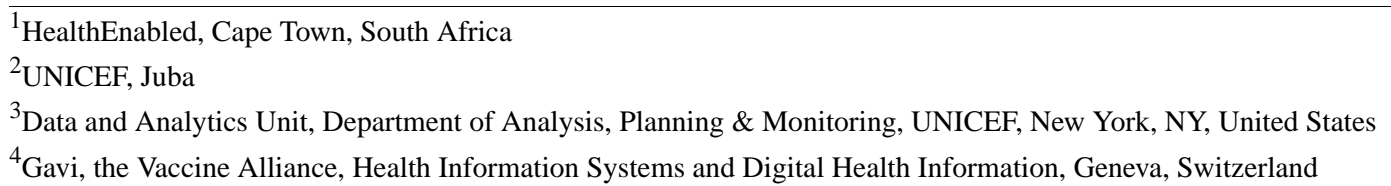

\section{Corresponding Author:}

Patricia Mechael, MHS, PhD

HealthEnabled

6 Wherry Road, Muizenberg

Cape Town

South Africa

Phone: 27217010766

Email:patty@healthenabled.org

\begin{abstract}
The effective use of geospatial data and technologies to collect, manage, analyze, model, and visualize geographic data has great potential to improve data-driven decision-making for immunization programs. This article presents a theory of change for the use of geospatial technologies for immunization programming - a framework to illustrate the ways in which geospatial data and technologies can contribute to improved immunization outcomes and have a positive impact on childhood immunization coverage rates in low- and middle-income countries. The theory of change is the result of a review of the state of the evidence and literature; consultation with implementers, donors, and immunization and geospatial technology experts; and a review of country-level implementation experiences. The framework illustrates how the effective use of geospatial data and technologies can help immunization programs realize improvements in the number of children immunized by producing reliable estimates of target populations, identifying chronically missed settlements and locations with the highest number of zero-dose and under-immunized children, and guiding immunization managers with solutions to optimize resource distribution and location of health services. Through these direct effects on service delivery, geospatial data and technologies can contribute to the strengthening of the overall health system with equity in immunization coverage. Recent implementation of integrated geospatial data and technologies for the immunization program in Myanmar demonstrate the process that countries may experience on the path to achieving lasting systematic improvements. The theory of change presented here may serve as a guide for country program managers, implementers, donors, and other stakeholders to better understand how geospatial tools can support immunization programs and facilitate integrated service planning and equitable delivery through the unifying role of geography and geospatial data.
\end{abstract}

(J Med Internet Res 2021;23(8):e29759) doi: 10.2196/29759

\section{KEYWORDS}

geospatial data; immunization; health information systems; service delivery; equity mapping; theory; framework; children; immunization; vaccine; equity; geospatial; data; outcome; coverage; low- and middle-income; LMIC

\section{Introduction}

Maps are powerful tools for public health decision-makers to better understand the relationship between the location of populations and health system resources, indicators or predictors of health status, and their patterns over space and time. The visual power of the map is aided by modern advances in technology, computing, and handheld devices that can record the location of any place on the earth and transmit geospatial data for analysis, sharing, and use. The use of geography to analyze patterns of disease, distribution of populations, and 
inventories and locations of health services come together to create a catalyst for improving health systems.

Immunization programs in low- and middle-income countries are beginning to harness digital maps and geospatial data to display and analyze complex information for program improvements [1-6]. The effective use of geospatial data can show program managers which locations have not received adequate immunization services, provide more accurate denominators, and inform what vaccination delivery strategies should be used to optimize coverage and equity. It can also improve monitoring of immunization programs.

Applications of geospatial technologies for immunization are often approached as simple solutions to system challenges without careful consideration of the greater ecosystem or planning for widespread adoption and sustainability [7]. Interventions are often deployed as pilot technology-focused projects without sustained resources or commitment to support the underlying enabling environment, human capacities, and governance systems that will contribute to a long-lasting impact on decision-making and health outcomes [8]. Gavi, the Vaccine Alliance, supports a systematic approach to understanding the range of geospatial data and technology implementation experiences to guide sustainable and effective systems and governance for improving immunization services that can reach every child with life-saving vaccines while strengthening primary health care systems [9]. Geospatial data and technology applications for immunization align with GAVI's 2021-2025 strategy and the global Immunization Agenda 2030 strategy $[9,10]$. In order to provide life-saving services to children who default on the vaccination schedule and "zero-dose" children who have never received a vaccine, new geo-enabled approaches to planning and delivering services are needed to expand the reach of effective vaccination for all children.

\section{Theory of Change}

Complex interventions benefit from collaborative efforts to understand the underlying series of events and changes that will lead to the desired result [11]. A theory of change is a process and framework to help describe this causal pathway and to support critical thinking throughout the project design, implementation, and evaluation cycle [11]. A theory of change for the use of geospatial technologies for immunization programming describes the potential for geospatial technologies to contribute to real-world impacts by optimizing routine immunization program design, implementation, and monitoring to reach all children with immunization services (Figure 1). It was developed as part of a collaboration between GAVI and UNICEF (United Nations Children's Emergency Fund) to review the state of evidence in the published and grey literature and through consultations with implementers, donors, immunization, and geospatial technology experts, as well as country-level implementation teams [12]. The theory of change is meant to guide future investment and planning of geospatial technologies and systems for immunization programs within a broader context of health system strengthening, to coordinate donor and partner collaboration, and optimize investments in foundations and systems for long-term sustainability and effective use of immunization data for decision-making.

Figure 1. Theory of change for the use of geospatial technologies for immunization programing (originally published and adapted from [12]), with permission from Gavi, UNICEF, and HealthEnabled.

\begin{tabular}{|c|c|c|c|}
\hline \multicolumn{4}{|c|}{ Reduction in Childhood Disability and Mortality Due to Vaccine-Preventable Diseases } \\
\hline Immunization Impe & \multicolumn{3}{|c|}{$\begin{array}{l}\geq 80 \% \text { of children fully immunized in all districts and equitable coverage across population subgroups based on geographic, socio- } \\
\text { economic and cultural differences }\end{array}$} \\
\hline \multicolumn{4}{|c|}{ Improved immunization campaigns and routine immunization programs } \\
\hline $\begin{array}{l}\text { Immunization } \\
\text { Outcomes }\end{array}$ & $\begin{array}{l}\text { Increased number of children } \\
\text { immunized through improved } \\
\text { target setting }\end{array}$ & $\begin{array}{l}\text { Optimized immunization resource distribution } \\
\text { and location of services }\end{array}$ & $\begin{array}{l}\text { Improved quality, timeliness, and perception } \\
\text { of immunization services with equity in } \\
\text { coverage between communities }\end{array}$ \\
\hline $\begin{array}{l}\text { Geospatial Data } \\
\text { and Technologies } \\
\text { Outputs }\end{array}$ & $\begin{array}{l}\text { Improved identification of zero dose } \\
\text { and under-immunized children } \\
\text { through more accurate } \\
\text { microplanning and identification of } \\
\text { missed settlements to implement } \\
\text { appropriate vaccination strategy }\end{array}$ & $\begin{array}{l}\text { Improved planning and allocation of } \\
\text { immunization resources through strengthened } \\
\text { use of geospatial data, analysis and } \\
\text { visualisation }\end{array}$ & $\begin{array}{l}\text { Improved service delivery through better } \\
\text { planning, monitoring and tracking of } \\
\text { immunization activities for rapid problem } \\
\text { identification and corrective action }\end{array}$ \\
\hline $\begin{array}{l}\text { Geospatial Data } \\
\text { and Technologies } \\
\text { Inputs }\end{array}$ & $\begin{array}{l}\text { Produce and regularly update } \\
\text { digital maps for health area planning } \\
\text { based on health resources mapping } \\
\text { through a participatory process } \\
\text { involving local health staff to map } \\
\text { immunization resources }\end{array}$ & $\begin{array}{l}\text { Optimize distribution of resources (workforce, } \\
\text { funding, vaccines and supplies) based on more } \\
\text { accurate target population distribution and } \\
\text { identification of gaps in coverage and } \\
\text { immunization service accessibility based on } \\
\text { geospatial accessibility analysis, coverage } \\
\text { modelling, forecasting and other new } \\
\text { innovations and applications }\end{array}$ & $\begin{array}{l}\text { Track service delivery by location of } \\
\text { vaccinator activities and geographically- } \\
\text { linked notifications, immunization sessions, } \\
\text { supervision and allocation of financial } \\
\text { resources }\end{array}$ \\
\hline $\begin{array}{l}\text { Geospatial Data } \\
\text { \& Immunization } \\
\text { Foundations }\end{array}$ & \multicolumn{3}{|c|}{$\begin{array}{l}\text { Health System Mapping (essential): Develop and maintain master lists and data standards for health facilities, vaccination delivery sites } \\
\text { and cold chain, settlements, infrastructure, health area boundaries and other core geographic objects } \\
\text { Population Estimation (essential): Generate and use accurate population estimates (human density and distribution) to establish targets } \\
\text { (denominators) in immunization program planning } \\
\text { Analytics \& Modeling for Accessibility, Coverage, and Surveillance Planning and Monitoring (when possible): Use modeling to understand } \\
\text { geographic accessibility to services, vaccine distribution, and immunization coverage with links to data (through HIS, IHRIS, and eLMIS) } \\
\text { on vaccine-preventable diseases and adverse events following immunization (AEFI) }\end{array}$} \\
\hline Enablers & \multicolumn{3}{|c|}{$\begin{array}{l}\text { - Clearly defined vision, strategy and plan for a geo-enabled HIS/immunization program } \\
\text { - Information system governance structure including custodianship of geospatial data and technologies } \\
\text { - Policies supporting and enforcing the strategy and governance, including data accessibility } \\
\text { technologies and innovations over the long-term }\end{array}$} \\
\hline
\end{tabular}




\section{Evidence From Research and Implementation Experiences}

\section{Overview}

Geospatial data and technologies contribute to the following three interrelated immunization outcomes in the theory of change that together strengthen immunization campaigns and routine immunization program coverage and equity:

1. Increase the number of children immunized through improved target setting

2. Optimize immunization resource distribution and location of services

3. Improve the quality, timeliness, and perception of immunization services with equity in coverage between communities

These three outcome pillars are supported by foundations and enablers in the health system and a foundation of essential data that serve to guide the collection, management, and sustainable use of geospatial data and technologies for health. The theory of change is based on evidence and implementation experiences described for each of the three expected outcomes below.

\section{Increase the Number of Children Immunized Through Improved Target Setting}

Despite years of improvements in global vaccination coverage and strengthening systems for service delivery, many children remain underimmunized or never come in contact with routine immunization programs [13]. Delivering life-saving immunization services to all children requires an enormous amount of coordination, planning, and resources; microplans are the local-level operational workplans used by immunization managers to systematically compile relevant local data, prioritize activities, maintain adequate stock, and find solutions to service delivery barriers [14]. UNICEF and the World Health Organization (WHO)'s Reach Every District (RED) strategy encourages the use of maps for local-level microplanning activities, which are traditionally hand-drawn sketches of the catchment area based on local knowledge [15]. These sketch maps are often not to scale; inaccurate or incomplete; and do not contain crucial information for microplanning such as distances, road conditions, or geographic barriers that may delay or discourage vaccinator teams from reaching remote areas during door-to-door campaign activities $[3,16]$. Health system data may contain overlapping borders; settlements that fall outside health boundaries; and inconsistencies in naming, spelling, and classification of service delivery units and settlements $[2,4]$. The planning tools and delivery strategies to reach all children with immunization services need to expand beyond the current methods to incorporate new digital tools that support local immunization managers to identify and reach areas that have been historically left off maps and microplans [17].

Children who have never received a vaccination can be clustered in settlements or neighborhoods, increasing their risk of contracting a vaccine-preventable disease without the benefit of herd immunity in their communities $[18,19]$. Due to a variety of socioeconomic and geographic barriers, these children are left "off the map" both literally and figuratively. Geospatial data and technologies for immunization programming can help identify these underreached communities by pinpointing the physical location of all settlements relative to the area's immunization service delivery locations. Spatially accurate maps are created through a combination of satellite images and field-based data collection to georeference and validate landmarks, inhabited settlements, and infrastructure through a participatory process with district and local immunization managers. They are then used to plan and execute realistic action plans that include outreach activities. Microplans developed with geospatial technologies and data are a cost-effective way to identify settlements missed with traditional microplanning activities that rely on hand-drawn paper maps $[2,5,6,16]$. With more accurate and reliable information about the locations, characteristics, and number of settlements within their catchment area, managers can plan and prioritize their activities to vaccinate more children and monitor progress both from the local and central levels.

\section{Optimize Immunization Resource Distribution and Location of Services}

Deciding how many vaccinators are needed for each catchment area, how many vaccines to send, and where to deploy fixed and outreach vaccination services depends on the number of people being served in each area, their distribution in the area, and the current unmet need for immunization services. The target population, or denominator, is often estimated from the most recent national census, adjusted each year by adding a fixed rate of growth [16]. Unfortunately, outdated census data, variation in growth rates, and population migration and mobility contribute to overestimation of the target population, leading to wasted resources, or underestimation with subsequent shortages and unvaccinated children [16,20,21]. Even with good population estimates, the location of settlements in relation to services measured by distance or travel time impact access and coverage. There is a relationship between complete and timely vaccination status and shorter distance or travel time to the nearest vaccination service, demonstrating how important the location of immunization services and geographic accessibility is for maximal immunization coverage [1,22-25]. To calculate unmet need, aggregate vaccination coverage data for the entire country or province can hide pockets of low coverage and settlements with unvaccinated children, leaving these communities vulnerable to vaccine-preventable diseases [26,27]. These data limitations impact immunization program planning and resource distribution, thereby preventing the timely delivery of life-saving vaccines to all children.

Tools and approaches that utilize geospatial technologies can help immunization managers make more targeted decisions for where and how to focus activities and resources. Precise estimates of population density and distribution for small geographic areas can be generated with a combination of satellite image data, statistical modelling, and sampled survey information to create accurate program targets for planning and monitoring purposes $[28,29]$. Population distribution estimates can be combined with spatial data on the location of vaccine service posts, road and transportation infrastructure, and geographic barriers to quantify the movement opportunity for people to reach existing services, inform new strategies and 
location of services, and prioritize outreach activities to remote communities [30,31]. Modelled vaccination coverage for small subnational units of measurement can be generated using multiple sources of data to identify pockets with low coverage and, when combined with data on other socioeconomic indicators, can help suggest solutions to overcome the social, gender-related, economic, geographic, or other factors that are preventing access to immunization services [32]. Improved granular data that is visualized to show geographic trends for local populations can help target delivery strategies and resources to increase immunization coverage in the areas that need it the most $[33,34]$.

\section{Improve the Quality, Timeliness, and Perception of Immunization Services With Equity in Coverage Between Communities}

A number of underlying factors contribute to nonvaccination-from service delivery challenges in the immunization program to community demand, including the caregiver's perceived quality of immunization services, trust, and respect within the community [35,36]. Pockets of communities that do not receive quality and timely immunization services are susceptible to vaccine-preventable disease outbreaks. Measuring and monitoring these geographic and socioeconomic pockets of inequality is the first step toward promoting equality in coverage [37,38]. Timely and accurate data on program performance such as tracking supply and logistics, frequency of outreach services, and drop-out-rates can be used to improve the quality of services by providing entry points for supportive supervision, improve planning, identify problems, and initiate rapid corrective action for better overall service delivery $[8,39]$. Vaccine-preventable disease surveillance systems require rapid communication of data that facilitate feedback up and down the surveillance chain for coordinated and appropriate investigation and response [40]. In order to respond quickly to gaps and challenges, local and subnational immunization managers need to have the skills to use data that is collected accurately, transferred quickly, and presented in a way that can trigger action [8].

Mobile technologies and cellular networks provide opportunities to improve data collection, transfer, analysis, and use [41]. The combination of near real-time communication with automatic collection of accurate location data enables field-based teams of vaccinators to report on the number and location of doses delivered and any barriers encountered during immunization campaigns into an integrated dashboard where managers can monitor progress and respond appropriately to challenges and missed communities [42-45]. These daily reports of progress during campaign activities can help inform the next day's strategy or provide evidence to extend or alter activities to reach all children in the target area [43-45]. For routine immunization services, supervisors can track the progress of mobile vaccination sessions as part of a geo-enabled digital microplan to identify and respond to missed settlements and improve monitoring of the microplan implementation $[3,46]$. The collection of geographic information linked to reports of suspected vaccine preventable diseases can facilitate rapid and coordinated action to prevent outbreaks, identify high-risk areas that need vaccination services, and facilitate risk-mapping to predict future outbreaks $[40,47]$. The transparent sharing of data can promote a common understanding of expectations and challenges between vaccinators and supervisors.

\section{Implementation Experiences: Myanmar Case Study}

The current knowledge base shows that geospatial data and technology applications for immunization have the potential to stimulate programmatic improvements and increase immunization coverage. However, real-life examples of comprehensive and sustainable systems using geospatial data and technologies for immunization are rare. Myanmar provides an example of how the process of integrating geospatial data and technology for immunization microplanning validates the progression of incremental steps outlined in the theory of change.

In 2016, the national immunization program in Myanmar undertook a review as part of a health system commitment to creating a geo-enabled health information system. The assessment uncovered gaps in immunization coverage for children living in geographically and socially hard-to-reach communities, such as migrant worker settlements, remote villages, ethnic minority communities, and conflict-affected areas [48]. The local-level operational immunization workplans lacked reliable population information, and boundaries were out of date. This limited the ability of health workers to plan and undertake the daily logistics of immunization service delivery. In response to these gaps in coverage, the program took steps to support the microplanning process with geospatial data and technologies.

A phased pilot approach began in late 2017 in one township to begin building foundations, local capacity, and standard procedures and to demonstrate the benefits of using geospatial data and technologies for local-level immunization microplanning [48]. Subsequent expansion to a larger region in 2018 built on the foundations and lessons learned from the first pilot, as well as made improvements in the processes and implementation approach. Each expansion phase to a new area lasted 6 to 9 months to ensure that local capacity and systems were strengthened along the way.

The field implementation process created an up-to-date geo-referenced master list of facilities, settlements, and health area boundaries. A master list establishes a standardized, complete, up-to-date, and uniquely coded list of all features essential to the delivery of immunization services. Through this collaborative process, standard definitions were established for the geographic objects relevant to the microplanning process (eg, vaccination sites, facilities, and communities), and procedures were established for standard data collection. Every location where people lived, including temporary migrant settlements, were identified, defined, and included in the master list. Satellite images aided in settlement identification and catchment area delineation. Health workers were important stakeholders in the process to validate and review the maps and make necessary adjustments to their immunization microplans based on available transportation routes, distances, and geographic features in coordination with their supervisors. Online and printed maps showing accurate spatial relationships 
between key immunization assets and communities were produced and made available for national immunization program staff to plan vaccination campaigns and routine service delivery.

The interim results from Myanmar's phased implementation approach include immediate effects of the collaborative process, map production, and distribution. With settlements and communities well defined, including characteristics and locations of temporary settlements, health workers were able to include these previously overlooked populations in their immunization microplans. The addition of missed settlements improved target population estimates, allowing for improvements in service delivery planning. The transparency and sharing of microplans and maps enabled supervisors to provide better support to health workers and encouraged accountability at all levels. Health officials were able to see the need for expanded health facility distribution with a clear visualization and accurate distances displayed in new microplanning maps.

These experiences validate the expected outputs for the integration of geospatial data and technologies in the theory of change (Table 1). Myanmar's process of integrating geospatial data and technologies for immunization microplanning demonstrates how the complex challenge of delivering effective vaccinations to every child in countries with underlying health system challenges can benefit from these applications. Based on the implementation experiences in Myanmar's program, it seems likely that continued expansion and improvements in the geo-enablement of their immunization program will lead to the desired immunization outcomes and overall expanded coverage as the theory of change suggests.

Table 1. Summary of geo-enabled microplanning implementation results from the Myanmar Central Expanded Program on Immunization.

\begin{tabular}{lcl}
\hline Myanmar's geo-enabled microplanning experiences & Corresponding geospatial data and technology theory of change output \\
\hline - & $\begin{array}{l}\text { Settlements that were previously missed are defined, identified, and } \\
\text { included in the microplan }\end{array}$ & $\begin{array}{l}\text { Improved identification of zero-dose and underimmunized children through } \\
\text { more accurate microplanning and identification of missed settlements to } \\
\text { - Visualization of accurate geospatial relationships in catchment areas } \\
\text { implement appropriate vaccination strategy }\end{array}$ \\
$\quad \begin{array}{l}\text { serve as a tool to plan vaccination sessions }\end{array}$ &
\end{tabular}

- $\quad$ Target population denominator is closer to actual community density and distribution

- Standardized definitions and categorization of settlements and immunization resources help streamline planning process

- Visualization serves as an advocacy tool to demonstrate to senior health officials the need for improvements in the equitable distribution and allocation of resources

- Enhanced geo-enabled microplanning process encourages accountability of health workers and supervisors with transparency and shared expectations and service delivery plans

Improved planning and allocation of immunization resources through strengthened use of geospatial data, analysis, and visualization

Additional lessons from Myanmar's experience reinforce the importance of the enabling environment and foundations in the theory of change, built on UNICEF's guidelines and detailed approach to support the enabling environment for geospatial data and technologies in immunization programs [49]. The high-level commitment to transition to a geo-enabled national health information system in the Department of Public Health in Myanmar, with support and technical guidance from the WHO, GAVI, UNICEF, and the Health GeoLab Collaborative (a center of excellence for the Asia-Pacific region) laid a strong foundation of advocacy, governance, policies, and capacity for the management and use of geospatial data and technologies in the broader health sector [50]. The geo-enhanced microplanning process was further supported by the creation of common master lists for the geographic objects essential to the immunization program, an element recommended in the theory of change as an essential foundation to the sustained and effective use of geospatial data and technologies for immunization programs. A commitment to improving the supportive environment with a dedicated plan and resources to address needs and gaps in these enablers and foundations will promote the sustainable and effective use of geospatial data and technologies and the application of future geospatial innovations for immunization programs.

Improved service delivery through better planning, monitoring, and tracking of immunization activities for rapid problem identification and corrective action

\section{Discussion: Applying the Theory of Change}

As more immunization programs begin to incorporate geospatial data and technologies to help achieve and measure improvements in equitable immunization service delivery, the theory of change for the use of geospatial technologies for immunization programming can guide discussions, decision-making, and consensus building for investment, development, and coordination. The theory of change represents a thought process aimed at understanding the underlying sequence of events that can contribute to sustained and effective improvements and should be considered a roadmap that is subject to change, improvements, and fine-tuning as more country-level experiences bring insights into best practices and real-world challenges. The three pillars and supportive foundations and enablers can help initiate conversations and identify needs and gaps in country immunization programs to make sound decisions for short-term and long-term planning and contribute to improving the broader health system through shared geospatial data, technologies, and resources.

The theory of change may also serve as a framework for operational research and evaluations by suggesting quantifiable 
research objectives that will contribute to the evidence base and help clarify the relationships and determinants of effective application and use of geospatial data and technologies. The use of geospatial data and technologies within immunization programs can improve not only the systematic collection and use of quality and transparent data for programming but also for measuring improvements and incremental achievements throughout the project cycle.

The framework presented here is grounded in lessons from a handful of implementation experiences and existing evidence from the literature. As more countries gain practical experiences in integrating geospatial data and technologies into national immunization programs, best practices will suggest improvements to this theory of change and will help guide other programs on the incremental steps, foundations, planning, and budgeting recommendations that contribute to the sustainable integration of spatial data for immunization programming. A number of global and regional centers are developing and testing practical guidance and also providing technical support, resources, and training to help national programs apply geospatial data and technologies for immunization and other health systems $[49,51,52]$.

\section{Conclusions}

Effective data use will be necessary to make additional gains in global immunization coverage. Technology can help improve the collection, visualization, and use of data to detect and address inequalities in coverage $[8,38]$. However, the quality and value of immunization data ultimately depends on the people who are collecting, analyzing, and using the data, not just the technology they are using [8]. Geospatial data and technologies are a means to an end. They can strengthen data-driven decision-making if they are aligned with immunization outcomes in ways that address program needs and reinforce people's confidence and trust in the resulting data products and analyses. Optimizing the deployment of immunization services to make them accessible for newly identified communities will pave the way for anchoring primary health care services in underserved areas. A focus on investing in and building sustainable and equitable health and immunization systems with strong leadership and capacity to use the geospatial tools and technologies that are appropriate for each country program will be critical for delivering life-saving vaccines to all children.

\section{Acknowledgments}

The authors thank the Monitoring an Evaluation team at the GAVI Secretariat and all the key informants for providing guidance on the original landscape and theory of change. Special thanks to Rocco Panceira at UNICEF for providing insights and suggestions on the manuscript. The research was supported by Gavi, the Vaccine Alliance (contract no. M\&E88730520).

\section{Authors' Contributions}

SCC led landscape analysis, evidence review, cases study development, and primary author of paper. PM led framing and co-authoring of the landscape; led development of theory of change; and contributed to the structure, review, and revision of the manuscript. NMT provided content for the case study on Myanmar experiences and performed an overall review of the manuscript. MSD provided technical guidance and reviewed and revised the manuscript. CG provided guidance, framing, and input for the landscape and theory of change, as well as technical guidance, review, and revision of the manuscript.

\section{Conflicts of Interest}

None declared.

\section{References}

1. Joseph NK, Macharia PM, Ouma PO, Mumo J, Jalang'o R, Wagacha PW, et al. Spatial access inequities and childhood immunisation uptake in Kenya. BMC Public Health 2020 Sep 15;20(1):1407 [FREE Full text] [doi: 10.1186/s12889-020-09486-8] [Medline: 32933501]

2. Dougherty L, Abdulkarim M, Mikailu F, Tijani U, Owolabi K, Gilroy K, et al. From paper maps to digital maps: enhancing routine immunisation microplanning in Northern Nigeria. BMJ Glob Health 2019;4(Suppl 5):e001606 [FREE Full text] [doi: 10.1136/bmjgh-2019-001606] [Medline: 31321093]

3. Gammino V, Nuhu A, Chenoweth P, Manneh F, Young RR, Sugerman DE, et al. Using geographic information systems to track polio vaccination team performance: pilot project report. J Infect Dis 2014 Nov 01;210 Suppl 1:S98-101. [doi: 10.1093/infdis/jit285] [Medline: 25316882]

4. Rosencrans L, Sume G, Kouontchou J, Voorman A, Anokwa Y, Fezeu M, et al. Mapping for health in Cameroon: polio legacy and beyond. J Infect Dis 2017 Jul 01;216(suppl_1):S337-S342 [FREE Full text] [doi: 10.1093/infdis/jix008] [Medline: 28838181]

5. Barau I, Zubairu M, Mwanza M, Seaman VY. Improving polio vaccination coverage in Nigeria through the use of geographic information system technology. J Infect Dis 2014 Nov 01;210 Suppl 1:S102-S110. [doi: 10.1093/infdis/jiu010] [Medline: 25316823]

6. Kamadjeu R. Tracking the polio virus down the Congo River: a case study on the use of Google Earth ${ }^{\mathrm{TM}}$ in public health planning and mapping. Int J Health Geogr 2009;8(1):4. [doi: 10.1186/1476-072x-8-4] 
7. Huang F, Blaschke S, Lucas H. Beyond pilotitis: taking digital health interventions to the national level in China and Uganda. Global Health 2017 Jul 31;13(1):49 [FREE Full text] [doi: 10.1186/s12992-017-0275-z] [Medline: 28756767]

8. Scobie HM, Edelstein M, Nicol E, Morice A, Rahimi N, MacDonald NE, SAGE Working Group on ImmunizationSurveillance Data QualityUse. Improving the quality and use of immunization and surveillance data: Summary report of the Working Group of the Strategic Advisory Group of Experts on Immunization. Vaccine 2020 Oct 27;38(46):7183-7197 [FREE Full text] [doi: 10.1016/j.vaccine.2020.09.017] [Medline: 32950304]

9. Gavi, the Vaccine Alliance strategy 2021-2025. Gavi, the Vaccine Alliance. 2021. URL: https://www.gavi.org/sites/default/ files/board/minutes/2019/Gavi\%20strategy\%202021-2025\%20one-pager.pdf [accessed 2021-02-28]

10. Cherian T, Hwang A, Mantel C, Veira C, Malvolti S, MacDonald N, et al. Global Vaccine Action Plan lessons learned III: monitoring and evaluation/accountability framework. Vaccine 2020 Jul 14;38(33):5379-5383 [FREE Full text] [doi: 10.1016/j.vaccine.2020.05.028] [Medline: 32430149]

11. Vogel I. Review of the use of Theory of Change in international development. UK Department of International Development. 2012. URL: https://assets.publishing.service.gov.uk/media/57a08a5ded915d3cfd00071a/DFID_ToC_Review_VogelV7. pdf [accessed 2021-01-10]

12. Gavi, The Vaccine Alliance, in Collaboration with UNICEF. 2020 Sep. URL: https://www.gavi.org/sites/default/files/ document/2020/GIS-and-Immunisation-Landscape_EN.pdf [accessed 2021-01-11]

13. MacDonald N, Mohsni E, Al-Mazrou Y, Kim Andrus J, Arora N, Elden S, et al. Global vaccine action plan lessons learned I: recommendations for the next decade. Vaccine 2020 Jul 14;38(33):5364-5371 [FREE Full text] [doi: 10.1016/j.vaccine.2020.05.003] [Medline: 32563607]

14. Reaching Every District (RED) - a guide to increasing coverage and equity in all communities in the African Region. World Health Organization. 2017. URL: https://www.afro.who.int/publications/ reaching-every-district-red-guide-increasing-coverage-and-equity-all-communities [accessed 2021-01-11]

15. Microplanning for immunization service delivery using the Reaching Every District ( RED) strategy. World Health Organization. 2009. URL: https://apps.who.int/iris/handle/10665/70450 [accessed 2021-01-11]

16. Ali D, Levin A, Abdulkarim M, Tijjani U, Ahmed B, Namalam F, et al. A cost-effectiveness analysis of traditional and geographic information system-supported microplanning approaches for routine immunization program management in northern Nigeria. Vaccine 2020 Feb 05;38(6):1408-1415 [FREE Full text] [doi: 10.1016/j.vaccine.2019.12.002] [Medline: 31924428]

17. Berkley S. Immunization needs a technology boost. Nature 2017 Nov 16;551(7680):273. [doi: 10.1038/d41586-017-05923-8] [Medline: 29144479]

18. Wiysonge C, Uthman O, Ndumbe P, Hussey GD. Individual and contextual factors associated with low childhood immunisation coverage in sub-Saharan Africa: a multilevel analysis. PLoS One 2012;7(5):e37905 [FREE Full text] [doi: 10.1371/journal.pone.0037905] [Medline: 22662247]

19. Herliana P, Douiri A. Determinants of immunisation coverage of children aged 12-59 months in Indonesia: a cross-sectional study. BMJ Open 2017 Dec 22;7(12):e015790 [FREE Full text] [doi: 10.1136/bmjopen-2016-015790] [Medline: 29275336]

20. Ghiselli M, Wilson I, Kaplan B, Waziri N, Sule A, Ayanleke H, et al. Comparison of micro-census results for Magarya Ward, Wurno local government area of Sokoto state, Nigeria, with other sources of denominator data. Data (Basel) 2019;4(1):20 [FREE Full text] [doi: 10.3390/data4010020] [Medline: 30956970]

21. Alegana VA, Atkinson PM, Pezzulo C, Sorichetta A, Weiss D, Bird T, et al. Fine resolution mapping of population age-structures for health and development applications. J R Soc Interface 2015 Apr 06;12(105):20150073 [FREE Full text] [doi: 10.1098/rsif.2015.0073] [Medline: 25788540]

22. Sasaki S, Igarashi K, Fujino Y, Comber AJ, Brunsdon C, Muleya CM, et al. The impact of community-based outreach immunisation services on immunisation coverage with GIS network accessibility analysis in peri-urban areas, Zambia. J Epidemiol Community Health 2011 Dec;65(12):1171-1178. [doi: 10.1136/jech.2009.104190] [Medline: 20961876]

23. Metcalf CJE, Tatem A, Bjornstad ON, Lessler J, O'reilly K, Takahashi S, et al. Transport networks and inequities in vaccination: remoteness shapes measles vaccine coverage and prospects for elimination across Africa. Epidemiol. Infect 2014 Aug 14;143(7):1457-1466. [doi: 10.1017/s0950268814001988]

24. Okwaraji YB, Mulholland K, Schellenberg J, Andarge G, Admassu M, Edmond KM. The association between travel time to health facilities and childhood vaccine coverage in rural Ethiopia. A community based cross sectional study. BMC Public Health 2012 Jun 22;12:476 [FREE Full text] [doi: 10.1186/1471-2458-12-476] [Medline: 22726457]

25. Hierink F, Okiro E, Flahault A, Ray N. The winding road to health: A systematic scoping review on the effect of geographical accessibility to health care on infectious diseases in low- and middle-income countries. PLoS One 2021;16(1):e0244921 [FREE Full text] [doi: 10.1371/journal.pone.0244921] [Medline: 33395431]

26. Takahashi S, Metcalf CJE, Ferrari MJ, Tatem AJ, Lessler J. The geography of measles vaccination in the African Great Lakes region. Nat Commun 2017 May 25;8:15585 [FREE Full text] [doi: 10.1038/ncomms15585] [Medline: 28541287]

27. Utazi CE, Thorley J, Alegana VA, Ferrari MJ, Takahashi S, Metcalf CJE, et al. High resolution age-structured mapping of childhood vaccination coverage in low and middle income countries. Vaccine 2018 Mar 14;36(12):1583-1591 [FREE Full text] [doi: 10.1016/j.vaccine.2018.02.020] [Medline: 29454519] 
28. Bharti N, Djibo A, Tatem AJ, Grenfell BT, Ferrari MJ. Measuring populations to improve vaccination coverage. Sci Rep 2016 Oct 05;5:34541 [FREE Full text] [doi: 10.1038/srep34541] [Medline: 27703191]

29. Tatem A. Mapping the denominator: spatial demography in the measurement of progress. Int Health 2014 Sep;6(3):153-155 [FREE Full text] [doi: 10.1093/inthealth/ihu057] [Medline: 25125576]

30. Blanford JI, Kumar S, Luo W, MacEachren AM. It's a long, long walk: accessibility to hospitals, maternity and integrated health centers in Niger. Int J Health Geogr 2012;11(1):24-15. [doi: 10.1186/1476-072x-11-24]

31. Ray N, Ebener S. AccessMod 3.0: computing geographic coverage and accessibility to health care services using anisotropic movement of patients. Int J Health Geogr 2008;7(1):63. [doi: 10.1186/1476-072x-7-63]

32. Cutts F, Dansereau E, Ferrari M, Hanson M, McCarthy KA, Metcalf CJE, et al. Using models to shape measles control and elimination strategies in low- and middle-income countries: A review of recent applications. Vaccine 2020 Jan 29;38(5):979-992 [FREE Full text] [doi: 10.1016/j.vaccine.2019.11.020] [Medline: 31787412]

33. Mosser J, Gagne-Maynard W, Rao P, Osgood-Zimmerman A, Fullman N, Graetz N, et al. Mapping diphtheria-pertussis-tetanus vaccine coverage in Africa, 2000-2016: a spatial and temporal modelling study. The Lancet 2019 May;393(10183):1843-1855. [doi: 10.1016/s0140-6736(19)30226-0]

34. Shikuku D, Muganda M, Amunga S, Obwanda EO, Muga A, Matete T, et al. Door-to-door immunization strategy for improving access and utilization of immunization services in hard-to-reach areas: a case of Migori County, Kenya. BMC Public Health 2019 Aug 07;19(1):1064 [FREE Full text] [doi: 10.1186/s12889-019-7415-8] [Medline: 31391028]

35. Streefland PH, Chowdhury AM, Ramos-Jimenez P. Quality of vaccination services and social demand for vaccinations in Africa and Asia. Bull World Health Organ 1999;77(9):722-730 [FREE Full text] [Medline: 10534895]

36. Favin M, Steinglass R, Fields R, Banerjee K, Sawhney M. Why children are not vaccinated: a review of the grey literature. Int Health 2012 Dec;4(4):229-238. [doi: 10.1016/j.inhe.2012.07.004] [Medline: 24029668]

37. Inequality monitoring in immunization: a step-by-step manual. World Health Organization. 2019. URL: https://apps.who.int/ iris/handle/10665/329535 [accessed 2021-01-11]

38. Chopra M, Bhutta Z, Chang Blanc D, Checchi F, Gupta A, Lemango ET, et al. Addressing the persistent inequities in immunization coverage. Bull. World Health Organ 2019 Jan 10;98(2):146-148. [doi: 10.2471/blt.19.241620]

39. Shen A, Fields R, McQuestion M. The future of routine immunization in the developing world: challenges and opportunities. Glob Health Sci Pract 2014 Dec 10;2(4):381-394. [doi: 10.9745/ghsp-d-14-00137]

40. Surveillance standards for vaccine-preventable diseases, 2nd ed. World Health Organization. 2018. URL: https://apps. who.int/iris/handle/10665/275754 [accessed 2021-07-22]

41. Kim SS, Patel M, Hinman A. Use of $\mathrm{m}$-Health in polio eradication and other immunization activities in developing countries. Vaccine 2017 Mar 07;35(10):1373-1379. [doi: 10.1016/j.vaccine.2017.01.058] [Medline: 28190744]

42. Bawa S, Shuaib F, Saidu M, Ningi A, Abdullahi S, Abba B, et al. Conduct of vaccination in hard-to-reach areas to address potential polio reservoir areas, 2014-2015. BMC Public Health 2018 Dec 13;18(Suppl 4):1312-1120 [FREE Full text] [doi: 10.1186/s12889-018-6194-y] [Medline: 30541501]

43. Haskew J, Kenyi V, William J, Alum R, Puri A, Mostafa Y, et al. Use of mobile information technology during planning, implementation and evaluation of a polio campaign in South Sudan. PLoS One 2015;10(8):e0135362 [FREE Full text] [doi: 10.1371/journal.pone.0135362] [Medline: 26252383]

44. Oh DH, Dabbagh A, Goodson JL, Strebel PM, Thapa S, Giri JN, et al. Real-time monitoring of vaccination campaign performance using mobile phones - Nepal, 2016. MMWR Morb Mortal Wkly Rep 2016 Oct 07;65(39):1072-1076 [FREE Full text] [doi: 10.15585/mmwr.mm6539a5] [Medline: 27711034]

45. Teng JE, Thomson DR, Lascher JS, Raymond M, Ivers LC. Using Mobile Health (mHealth) and geospatial mapping technology in a mass campaign for reactive oral cholera vaccination in rural Haiti. PLoS Negl Trop Dis 2014;8(7):e3050 [FREE Full text] [doi: 10.1371/journal.pntd.0003050] [Medline: 25078790]

46. Chandir S, Dharma VK, Siddiqi DA, Khan AJ. Feasibility of using global system for mobile communication (GSM)-based tracking for vaccinators to improve oral poliomyelitis vaccine campaign coverage in rural Pakistan. Vaccine 2017 Sep 05;35(37):5037-5042. [doi: 10.1016/j.vaccine.2017.07.026] [Medline: 28802756]

47. The importance of high-quality AFP surveillance data in the fight to eradicate polio. EHealth Africa - Building Stronger Health Systems in Africa. 2019 Feb 22. URL: https://www.ehealthafrica.org/blog/2019/2/18/ the-importance-of-high-quality-afp-surveillance-data-in-the-fight-to-eradicate-polio [accessed 2021-01-18]

48. The use of geospatial data and technologies in support of immunization microplanning in Myanmar Implementation Report (2017 - 2018). United Nations Children's Emergency Fund. 2018. URL: https://www.unicef.org/media/58036/file [accessed 2021-01-12]

49. Guidance on the use of geospatial data and technologies in immunization programs: overview and managerial considerations for in-country strengthening. United Nations Children's Emergency Fund. 2018. URL: https://www.unicef.org/media/ 58181/file [accessed 2021-01-12]

50. Ebener S, Roth S, Khetrapal S. Building capacity for geo-enabling health information systems: supporting equitable health services and well-being for all (ADB Briefing Paper no 88). Asian Development Bank. 2018. URL: https://www.adb.org/ publications/building-capacity-geo-enabling-health-information-systems [accessed 2021-01-12] 
51. Leveraging geospatial technologies and data to strengthen immunisation programmes. Gavi, the Vaccine Alliance, in collaboration with UNICEF. 2021 Apr. URL: https://www.gavi.org/sites/default/files/evaluations/

Leveraging-Geospatial-Technologies.pdf [accessed 2021-06-04]

52. WHO GIS Centre for Health. World Health Organization. URL: https://www.who.int/data/gis [accessed 2021-06-04]

\author{
Abbreviations \\ GAVI: Gavi, the Vaccine Alliance \\ RED: Reach Every District \\ UNICEF: United Nations Children's Emergency Fund \\ WHO: World Health Organization
}

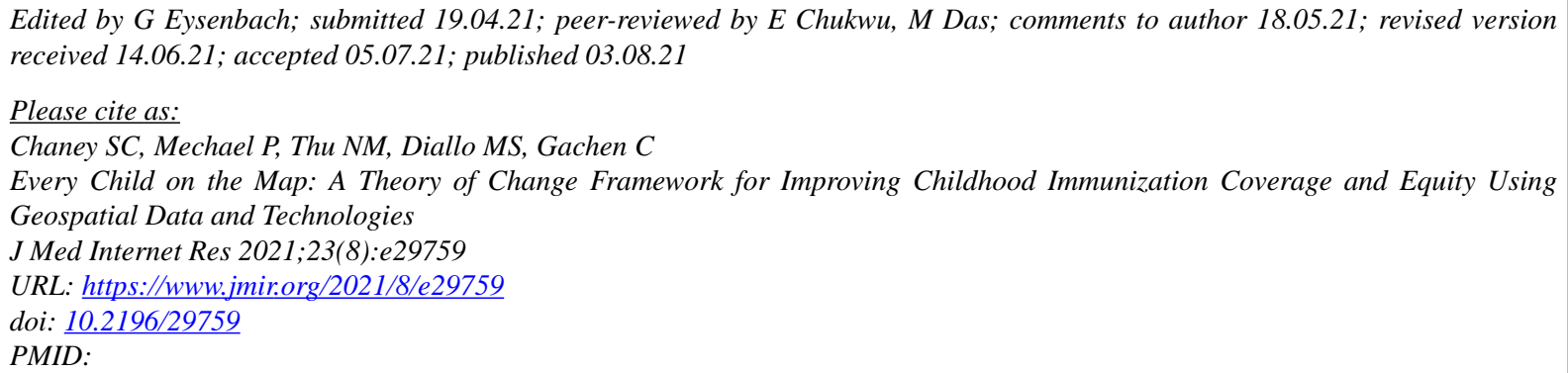

(C) Sarah Cunard Chaney, Patricia Mechael, Nay Myo Thu, Mamadou S Diallo, Carine Gachen. Originally published in the Journal of Medical Internet Research (https://www.jmir.org), 03.08.2021. This is an open-access article distributed under the terms of the Creative Commons Attribution License (https://creativecommons.org/licenses/by/4.0/), which permits unrestricted use, distribution, and reproduction in any medium, provided the original work, first published in the Journal of Medical Internet Research, is properly cited. The complete bibliographic information, a link to the original publication on https://www.jmir.org/, as well as this copyright and license information must be included. 